\title{
LOS JÓVENES EN LA CONSTRUCCIÓN: DINÁMICAS Y ACTORES EN DISPOSITIVOS DE EDUCACIÓN-FORMACIÓN-EMPLEO ${ }^{1}$
}

\author{
VERÓNiCA MillenaAR ${ }^{2}$, CAROLINA DuRsi $^{3}$, DELFINA GARINO $^{4}$, \\ Eugenia Roberti ${ }^{5}$, Alejandro Burgos ${ }^{6}$, Mariana Sosa ${ }^{7}$, Claudia JaCinto ${ }^{8}$
}

\begin{abstract}
RESUMEN
El trabajo se propone caracterizar circuitos de articulación entre educación, formación e inserción laboral en el sector de la construcción. Se reflexiona sobre la construcción social de los mismos en el mercado de trabajo juvenil. El estudio combina diferentes técnicas de investigación social: desde una estrategia cuantitativa, se procesaron datos secundarios acerca de la construcción; desde una estrategia cualitativa, se analizaron documentos y otras fuentes secundarias acerca de las políticas a nivel nacional, y entrevistas semiestructuradas a actores referentes de dichos circuitos. Los principales resultados muestran articulaciones recientes y un dinamismo apoyado por las políticas públicas, que evidencia esfuerzos en la creación de oportunidades educativas y de inserción laboral para los jóvenes.
\end{abstract}

\section{Palabras Claves: Formación; EdUCACIÓN; Políticas; EMPLEO JuVENIL}

\section{OS JOVENS NA CONSTRUÇÃO: DINÂMICAS E ATORES EM DISPOSITIVOS DE EDUCAÇÃO - FORMAÇÃO - EMPREGO}

\section{RESUMO}

O trabalho visa caracterizar circuitos de articulação entre educação, formação e inserção laboral no setor da construção e reflexionar sobre a construção social dos mesmos no

\footnotetext{
${ }^{1}$ Este artículo refleja algunos de los resultados de una investigación del Programa de Estudios sobre Juventud, Educación y Trabajo (PREJET) en el Centro de Investigaciones Sociales (CIS-CONICET) del Instituto de Desarrollo Económico y Social. La investigación forma parte del proyecto PICT BID 0091-2012 y del proyecto colaborativo apoyado por Norrag en Argentina y Sudáfrica, "Entendiendo las barreras de acceso a empleos decentes para los jóvenes".

${ }^{2}$ Socióloga Universidad de Buenos Aires y Magíster en Ciencias Sociales UNGS-IDES. Docente en la Universidad Metropolitana para la Educación y el Trabajo. E-mail: veronicamillenaar@gmail.com

${ }^{3}$ Socióloga por la Universidad de Buenos Aires y Doctoranda en Ciencias Sociales por la Universidad de Buenos Aires. Email: carolina.dursi@gmail.com

${ }^{4}$ Socióloga Universidad de Buenos Aires y Doctoranda de la Universidad de Buenos Aires. Docente en la Universidad Nacional del Comahue. E-mail: delgarino@gmail.com

${ }^{5}$ Socióloga Universidad Nacional de La Plata y Magister en Ciencias Sociales. Docente en la FAHCE UNLP. E-mail: eugenia.roberti@hotmail.com

${ }^{6}$ Lic. en Educación Universidad Nacional de General Sarmiento y Magíster en Educación Universidad de Buenos Aires (FFyL-UBA). E-mail: edgardoalejandroburgos@yahoo.com.ar

${ }^{7}$ Socióloga Universidad de Buenos Aires y Magíster en Sociología Económica del Instituto de Altos Estudios Sociales (IDAES/UNSAM). E-mail: marianalucs@gmail.com

${ }^{8}$ Socióloga Universidad de Buenos Aires y Dra. en Estudios de América Latina-Sociología, universidad Paris III, Investigadora CIS-IDES-CONICET. E-mail: claudiajacinto01@gmail.com
} 
mercado de trabalho juvenil. O estudo combina diferentes técnicas de pesquisa social: desde uma estratégia quantitativa, foram processados dados secundários sobre a construção; desde uma estratégia qualitativa, analisamos documentos e outras fontes secundárias com respeito às políticas nacionais e entrevistas semiestruturadas a atores referentes a estes circuitos. Os principais resultados mostram articulações recentes e um dinamismo apoiado pelas políticas públicas que evidencia esforços na criação de oportunidades educativas e de inserção laboral para os jovens.

Palavras-Chave: FormaÇÃo, EducaÇÃo, Políticas, EMPREGo JuVEnil.

\title{
YOUNG PEOPLE IN BUILDING SECTOR: DYNAMICS AND ACTORS IN EDUCATION-TRAINING- EMPLOYMENT SCHEMES
}

\begin{abstract}
This work is aimed at characterizing the articulation circuits among education, training and labor integration in the building sector, reflecting on the social construction of them in the youth labor market. The study blends different social research techniques; secondary data about building were quantitatively processed, whereas documents and other secondary sources about national policies, and semi-structured interviews to prominent people from such circuits were analyzed qualitatively. The main results show recent articulations and a dynamism based on public policies which reflect the efforts made for creating educational and labor insertion opportunities for young people.
\end{abstract}

Keywords: Training, EduCAtion, Policies, Youth EMPloyment.

\section{INTRODUCCIÓN}

La inserción laboral de los jóvenes constituye un conjunto de procesos desplegados en mercados de trabajo heterogéneos y segmentados. En ellos, la educación y la formación, tanto profesional como en el espacio laboral, ocupan lugares diferenciados según segmentos, sectores productivos y territorios. La organización del trabajo, las relaciones profesionales y sus regulaciones, y los sistemas de formación se articulan a partir de una historia y una configuración de actores, reglas y normas propias de cada sociedad. Es por ello que el empleo de los jóvenes puede ser considerado un fenómeno construido socialmente, donde las políticas públicas, los propios sujetos jóvenes y los circuitos de educación-formación conforman diferentes "mundos del trabajo" (Dubar, 2001).

Este artículo se propone profundizar las heterogeneidades en la constitución de esos "mundos del trabajo" juveniles, a partir del análisis de un sector de actividad: la construcción en el periodo 2003-20139.

El sector seleccionado se caracteriza por presentar alta informalidad y gran heterogeneidad de unidades productivas, lo cual ha contribuido a la configuración de circuitos diferenciados de educación-empleo según niveles educativos y de calificaciones

\footnotetext{
9 Este artículo se inserta en el marco de un proyecto de investigación PICT2012-0091"Los modos de gestión de la inserción laboral de los jóvenes en distintos "mundos" del trabajo. Políticas públicas, dispositivos y trayectorias laborales de los jóvenes”, financiado por la ANPCyT y dirigido por Claudia Jacinto.
} 
puestas en juego. A su vez, se trata de un sector donde los jóvenes representan una parte considerable de la fuerza de trabajo, siendo, al mismo tiempo, un sector importante dentro del empleo juvenil. En ese marco, ¿cómo intervienen los dispositivos dirigidos a los jóvenes para formar y facilitarles el acceso a empleos mejores que los que podrían obtener sin pasar por esos circuitos? ¿Qué transformaciones recientes han experimentado los mismos, vinculadas a las políticas públicas de formación y empleo? Las tramas impulsadas por el dinamismo del sector y de las políticas, ¿han logrado incidir diferenciadamente en la construcción social de circuitos de inserción laboral para los jóvenes?

Con estos interrogantes, se han analizado las dinámicas recientes del sector y se han seleccionado (a partir de una muestra de casos estratégicamente elegidos) tres dispositivos de educación-formación-empleo relevantes. Los dispositivos han estado influidos por transformaciones recientes de las políticas públicas: el fuerte impulso a la educación técnica y la formación profesional; la extensión de la obligatoriedad a la educación secundaria; la búsqueda de nuevas estrategias para la inclusión en la misma; y la ampliación de las concepciones del mundo del trabajo (desde el empleo formal a la economía solidaria). Específicamente, orientaremos la discusión a partir de las siguientes hipótesis de trabajo:

1) A pesar de que el sector de la construcción entre 2003-2014 ha sido central en la reactivación económica y ha adquirido un dinamismo impulsado por la obra pública, la informalidad continúa siendo un rasgo característico del sector, por lo cual la inserción laboral de los jóvenes sigue manteniendo parámetros de muy alta informalidad.

2) Dadas las características del sector, los dispositivos de educación-formación-empleo identificados se vinculan con distintos sub-segmentos del mundo del trabajo: a) circuito establecido entre formación profesional y relación con empleo formal, pero siendo predominante el vínculo con el auto-empleo; b) circuito establecido entre secundaria técnica y prácticas profesionalizantes en empleos formales (acercamiento pero sin puente con la inserción laboral); c) circuito establecido entre secundaria y economía social (auto-empleo o empleo cooperativo).

3) Impulsados por el rol activo de las políticas públicas recientes, algunos circuitos de formación-empleo evidencian esfuerzos en fortalecer sus vínculos, "entramándose" más fuertemente con el mundo del trabajo, incluso ampliando la concepción del mismo. Sin embargo, si bien comparten un foco en los procesos formativos y en la orientación, presentan dificultades en la intermediación de los jóvenes hacia empleos decentes. Al mismo tiempo, presentan incidencias subjetivas que fortalecen las subjetividades de los trabajadores a través de nuevos saberes vinculados a sus derechos e identidades profesionales.

El estudio se estructura en tres apartados. Primero, se aborda la idea de "mundos del trabajo" y los entramados de actores en sectores de actividad específicos, haciendo énfasis en el sector de la construcción. Segundo, se analiza el dinamismo del sector en el periodo, la persistencia de la informalidad y la aparición de nuevas heterogeneidades, en el marco de las cuales se desarrollan los procesos de inserción laboral de jóvenes. Tercero, se examinan diversos circuitos de educación-formación-empleo de jóvenes en el sector, que establecen vínculos diferenciados con distintos segmentos del mundo del trabajo. 


\section{LA CONSTRUCCIÓN SOCIAL DE "MUNDOS DE LA INSERCIÓN": EDUCACIÓN, FORMACIÓN PROFESIONAL Y TRABAJO}

Numerosos trabajos han estudiado distintos niveles de las problemáticas de la inserción laboral de los jóvenes. Variables sociológicas clásicas de diferenciación tales como el sexo, el tramo etario, el nivel socio-económico y el nivel educativo, asociado a la inserción de jóvenes, han sido abundantemente tratadas en nuestro medio. Muchos trabajos vinculan las oportunidades de inserción a los ciclos económicos y distintos momentos en las configuraciones socio-productivas del país (Pérez, 2008; Salvia, 2008), otros han aportado evidencias sobre la construcción de trayectorias laborales con alta rotación y niveles de precariedad a nivel cuantitativo (Jacinto y Chitarroni, 2010). Asimismo, los estudios de trayectorias laborales cualitativos han dado relevancia a la construcción biográfica juvenil y su relación con los condicionantes estructurales y las estrategias de los sujetos (Dursi y Mereñuk, 2011; Millenaar, 2010). Sin embargo, los procesos de inserción han sido mucho menos explorados como una construcción social compleja. No se trata de procesos homogéneos, sino de "mundos de la inserción" (Dubar, 2001) diferenciados según tramas de empresas, intermediarios del empleo, instituciones educativas y de formación profesional, y segmentos de jóvenes socialmente identificables que se vinculan en el proceso de la inserción.

Dos características estructurales de las relaciones educación-trabajo en Argentina llevan a preguntarse sobre la construcción social de la inserción como producto de esos entramados de actores. Una primera característica, que concierne al mercado de trabajo, se reconoce en la fuerte y persistente informalidad laboral que se vincula a mecanismos no formales de acceso al empleo. El sector informal afecta en la actualidad a 4 de cada 10 trabajadores. El problema es más elevado entre los trabajadores independientes, donde la incidencia es cercana al $60 \%$, que entre los trabajadores asalariados, donde representa el $35 \%$ (Bertranou et al., 2011).

Una segunda característica, el vínculo entre nivel educativo y trabajo, se encuentra en la relación -no necesariamente lineal- entre años de escolaridad y acceso a más y mejores empleos. La credencial educativa tiene un valor relativo como han mostrado numerosos estudios al respecto, y poco se conoce acerca de la incidencia de otros tipos de formación. Por ejemplo, la formación profesional y otras formas de capacitación, e incluso la educación de adultos, sólo han sido abordadas en estudios puntuales (Jacinto y Millenaar, 2010).

De modo que, a priori, no se puede menos que intuir que sólo una parte de la inserción se construye en los circuitos instituidos de educación-formación-trabajo. Así, los mundos del trabajo se presentan segmentados no sólo según una compleja trama de tipos de empresas y de empleos, sino también de sectores de actividad y espacios locales. Uno de los objetivos de la investigación en la que se basa este artículo, justamente se adentra en preguntarse sobre las estrategias que diferentes actores institucionales construyen de cara a los "mundos de la inserción". ¿Cómo se coordinan (o no) las empresas, los actores educativos, los agentes que actúan en la intermediación del empleo? ¿Lo hacen considerando procesos de inserción laboral de jóvenes de perfiles socialmente identificables?

Con estas preocupaciones, la investigación se centró en los "mundos" gestionados por parte de una configuración de actores, en particular los vinculados a dispositivos públicos 
de formación y empleo. Se consideraron programas de formación profesional, orientación e intermediación laboral, prácticas y pasantías laborales, y programas de apoyo a emprendimientos productivos. Todos estos dispositivos han apuntado especialmente a jóvenes desempleados o con escaso acceso al empleo formal, generalmente con niveles de calificación medios y/o bajos, con el objeto de apoyarlos en sus primeras transiciones laborales.

Analizar la construcción social de estos "mundos de la inserción" es particularmente pertinente porque en años recientes las políticas públicas de educación, formación y empleo tuvieron un particular dinamismo que se evidenció en el desarrollo de planes sectoriales de formación profesional (FP), en políticas activas de empleo como el programa "Jóvenes con Más y Mejor Trabajo" (PJMMT), en planes de mejora de centros de Formación Profesional y en ampliación de los formatos y oferta de la Educación de Jóvenes y Adultos. Este mundo de dispositivos públicos, se vincula con puestos en empresas subvencionados por el Estado, auto-empleo, empleos precarios en la economía social, etc. En efecto, los dispositivos de formación y empleo se despliegan y construyen en un marco de relaciones sociales desiguales (de posición social, de género y etaria), las cuales limitan sus probabilidades de intervenir como estrategias de integración laboral y de mejoramiento de las condiciones laborales; pero, al mismo tiempo, no puede sostenerse que sean sólo instrumentos de reproducción, ya que tanto las políticas como las estrategias institucionales de los actores participantes en algunos casos se dirigen a objetivos de redistribución social. Tampoco puede presumirse que exista una racionalidad única común a todos los actores de la inserción. Esas articulaciones siempre se producen relacionalmente (Martin y Della Torre, 2012). Así, en cada uno de los dispositivos conviven diferentes lógicas, que muchas veces son colaborativas a la vez que conflictivas (Jacinto, 2014).

Para el análisis de los distintos entramados partimos de una serie de categorías desarrolladas en proyectos anteriores (Jacinto, 2010), incluyendo en esta oportunidad dimensiones vinculadas especialmente al análisis de las articulaciones entre actores. Las categorías de análisis a nivel institucional fueron:

1. El tipo de formación para el trabajo, los niveles educativos y de calificación que implican, la institucionalidad (a nivel macro-institucional) de la que dependen, las regulaciones y los roles de diferentes actores a nivel macro, y el nivel de calificación implicado en la formación.

2. El tipo de institución en la que se asienta la formación: desde la escuela secundaria, los centros de formación profesional regulares y otras organizaciones o instituciones que participan, tales como organizaciones de la sociedad civil, las empresas y los servicios de empleo.

3. Los grupos poblacionales a los que se dirigen, los requisitos de niveles educativos previos y formas de abordaje de sus restricciones y desventajas.

4. Los tipos de empleo a los que apuntan. Esencialmente, cómo conceptualizan la heterogeneidad de las oportunidades de empleo juvenil; qué conciben como "empleo de calidad o decente"; cómo valoran la generación de auto-empleo y/o empleo cooperativo por parte de los jóvenes.

5. Los propósitos de intervención concreta en los procesos de inserción laboral, es decir, en crear puentes de acceso al empleo (bolsas de trabajo, intermediación, búsqueda de empleo, etc.) y el tipo de empleos de los que se trata. 
A su vez, las categorías de análisis particularmente referidas a las tramas entre actores fueron las siguientes:

6. Los tipos de actores que participan en las tramas (referido a los mencionados en el punto 2)

7. Los tipos de recursos logrados a partir de esas relaciones inter-institucionales (por ejemplo, financiamiento institucional, docente, obtención de materiales, desarrollo curricular, orientación socio-laboral, certificación de los trabajadores, etc.)

8. Las tensiones visualizadas en las posibilidades de incidir en la inserción laboral del sector productivo. Entre ellas, las referidas a:

a) las condiciones del mercado de trabajo del sector (por ejemplo, alto nivel de informalidad, de empleo);

b) las condiciones de la oferta de formación (calidad, recursos, superposición de ofertas, distancia de la formación con requerimientos de puestos de trabajo);

c) las propias relaciones institucionales entre los actores (relaciones permanentes/efímeras; institucionales/ocasionales; intereses compartidos/en tensión, etc.).

Con este marco, analizamos las tensiones que se producen entre el mercado de trabajo en la construcción, los impulsos de las políticas públicas y las tramas que despliegan las instituciones de formación.

Metodológicamente, se combinaron diferentes técnicas de investigación social adoptando una triangulación metodológica y de fuentes de datos: desde una estrategia cuantitativa, se procesaron datos secundarios acerca de la construcción. A partir del procesamiento propio de la base de micro-datos de la Encuesta Permanente de Hogares realizada por el Instituto Nacional de Estadísticas y Censos (INDEC), se ha dado cuenta de la evolución del sector en la última década y la importancia relativa del empleo de los jóvenes entre 15 y 30 años en el mismo. Asimismo, se procesaron datos con el fin de analizar las principales características vinculadas al empleo en el sector (relacionadas a la edad, sexo, nivel educativo, calificación y calidad del empleo). Por otro lado, desde una perspectiva cualitativa, a partir de relevamientos de datos secundarios y entrevistas ${ }^{10}$, se mapeó la oferta de las instituciones de formación técnica y profesional. En esta línea, estudiamos los circuitos conformados por actores institucionales de educación-formaciónempleo que intervienen en las redes de inserción laboral de los jóvenes en el sector de la construcción. Esto incluye a las empresas (su proceso de selección de personal, la demanda de cualificaciones y estrategias de formación de sus empleados) y los diferentes programas que ofrecen formación para el trabajo (formación profesional, la educación técnica secundaria, programas de trabajo y/o segunda oportunidad educativa para los jóvenes, programas de capacitación para el trabajo en la escuela secundaria, entre otros).

A partir de un análisis específico y comparativo de material documental y entrevistas semi-estructuradas, se identificaron circuitos que unen la educación, la formación y la inserción laboral en el sector de actividad seleccionado. La integración

\footnotetext{
10 Desde el punto de vista de las técnicas de investigación cualitativa, analizamos documentos oficiales (decretos, resoluciones, leyes) e investigaciones anteriores; también desarrollamos 35 entrevistas semi-estructuradas con funcionarios públicos y otros informantes clave, como representantes de sindicatos, de empresas y directivos de instituciones formativo-educativas, entre otros. Cabe aclarar que en una etapa futura de la investigación se prevé realizar entrevistas con jóvenes.
} 
sistemática de la información obtenida permitió seleccionar tres tipos de oferta que apuntan a distintos segmentos del mercado de trabajo, con el fin de examinar la interacción dinámica entre los diferentes actores vinculados al sector (empresas, sindicatos, centros de formación, escuelas, etc.).

De este modo, los tres casos analizados son: un centro de formación profesional (CFP) de origen sindical, programas de prácticas profesionales en la educación media técnica, y una experiencia de educación secundaria con orientación en economía social, que incluye una formación en permacultura orientada al trabajo cooperativo.

\section{DINÁMICAS RECIENTES Y EMPLEO JOVEN EN EL SECTOR DE LA CONSTRUCCIÓN}

\subsection{Dinamismo del sector en la recuperación económica}

El sector de la construcción emplea actualmente al 10\% del total de ocupados en Argentina. Entre las principales características del sector se encuentran: el dinamismo, la heterogeneidad y el elevado nivel de informalidad.

Respecto al dinamismo, la recuperación económica posterior a la crisis de 2001 se vio reflejada en la reactivación de varias ramas de actividad a partir del año 2003. En esta etapa, el sector de la construcción cumplió un rol significativo en la salida de la crisis debido a que constituye una rama de actividad con amplia capacidad dinamizadora sobre el conjunto de la economía, tanto por su vinculación con otros sectores como por la demanda de empleo que genera (INET, 2009; Ruggirello, 2011; Miranda, 2012). A partir del análisis de los principales indicadores ligados al sector (PBI sectorial, ISAC ${ }^{11}$, Permisos de edificación) se observa que, tras el estallido de la crisis del año 2001, entre los años 2003 y 2006 se registró un notable crecimiento de la construcción, siendo uno de los sectores que manifestó mayor dinamismo. La variación anual del PBI sectorial entre 2002 y 2004 fue de $32 \%$ en promedio, pero a partir del año 2007 el ritmo de crecimiento se desaceleró y por momentos llegó a revertirse. La evolución de los tres indicadores revela la estrecha vinculación de la construcción con la tendencia general de la economía. La inversión pública tuvo una importancia significativa en el crecimiento del sector durante el periodo analizado. Las políticas ligadas a la promoción de la industria de la construcción y la vivienda jugaron un papel fundamental debido a que implicaron un fuerte impulso a la inversión en la obra pública y en el despliegue de programas vinculados al sector (Mingo et al., 2013). En el año 2002 la inversión pública representaba el 8,3\% del total de inversión en la construcción y mantuvo una tendencia ascendente, alcanzando a partir del año 2006 niveles cercanos al 20\% del total. Si se añade la vivienda financiada por el Estado, en 2006 la participación de la inversión pública asciende al 30\% (INET, 2009; Ruggirello, 2011).

\footnotetext{
${ }^{11}$ El Indicador Sintético de Actividad de la Construcción (ISAC) es un indicador confeccionado por el INDEC.
} 
Consistentemente, tras la salida de la crisis económica, la industria de la construcción cumplió un importante rol como demandante de mano de obra. La participación de ocupados en el sector aumentó, alcanzando niveles cercanos al 10\% en relación al total de ocupados en el país. Entre los años 2003 y 2014, el total de ocupados en el sector creció (especialmente entre 2003 y 2007), lo mismo sucedió si se observa la participación porcentual de ocupados en el sector de la construcción sobre el total de ocupados pasó de 6,9\% en 2003 a 9,2\% en 2013 (Sosa, 2015).

El sector presenta heterogeneidades según el tamaño de las empresas. Respecto de las unidades de producción y de las condiciones de formalidad existen, por un lado, grandes empresas que utilizan tecnología actualizada, ofrecen empleos que requieren mayor capacitación y sus trabajadores cuentan con protección sindical y cobertura de salud. Por otro lado, hay empresas intermedias que trabajan en el sector secundario, que emplean menos tecnología que las anteriores y sus trabajadores no suelen estar agremiados ni contar con cobertura de salud (Miranda, 2012; Pastrana, et al., 2008). Estas unidades pueden ser formales o informales y, aunque estén registradas, pueden tener empleados en condiciones de informalidad. Predominan relaciones de parentesco, amistad o vecindad entre los trabajadores. Finalmente, los trabajadores que se desempeñan en establecimientos de hasta cinco personas por lo general no trabajan en obras en construcción, sino que realizan numerosas tareas que fundamentalmente no son registradas, este es el caso, por ejemplo, de la reparación o las mejoras y ampliaciones realizadas en viviendas (Bertranou y otros, 2011). En el caso de los trabajadores independientes, el porcentaje de los ocupados que realiza obras en viviendas o locales del cliente asciende casi al 90\%.

\subsection{Perfiles educativos y calificaciones puestas en juego}

Puede identificarse, en la estructura ocupacional de las empresas, considerables heterogeneidades en las posiciones, las calificaciones y los saberes puestos en juego. Los estudios convergen en señalar que habitualmente las grandes y medianas empresas cuentan con un área gerencial-administrativa, y con trabajadores que desempeñan sus tareas en las obras propiamente dichas, profesionales y obreros. En ambos espacios de trabajo suele haber personal en relación de dependencia, trabajadores tercerizados y trabajadores independientes o externos. Como consecuencia de los controles que realiza el Estado y el sindicato, en este tipo de empresas todo el personal -sin importar la forma de contrataciónsuele estar protegido con todos los requisitos de la ley ${ }^{12}$. Por su formación, los egresados de escuelas técnicas son valorados en el sector y es frecuente que ocupen puestos de trabajo especializados tanto en las oficinas como en las obras propiamente dichas, según la especialidad de la que egresaron, así como posiciones directivas como jefes de sector, y pueden ocupar cargos en las administraciones de las obras cuando poseen conocimientos del área administrativo-contable.

Las grandes y medianas empresas suelen tener pocos obreros en relación de dependencia y trabajar con empresas subcontratistas. Por ejemplo, una cuadrilla "tipo" de

\footnotetext{
${ }^{12}$ Las empresas contratistas son solidariamente responsables de los subcontratistas, lo cual significa que, en caso de que el subcontratista no cumpla con el pago de las cargas sociales de los trabajadores y esta situación sea detectada, la compañía contratista debe responder por dichas cargas y eventuales multas. Esta situación incide en que las compañías generalmente trabajen con los mismos subcontratistas a lo largo de los años.
} 
trabajadores, que depende del subcontratista -quien recluta y dirige a los trabajadores-, suele estar compuesta por el oficial especializado, que es el capataz de esa célula de trabajo y quien obtiene mayores ingresos; ayudantes, que realizan tareas generales asistiendo al medio oficial y al oficial; el medio oficial, que tiene la capacidad de realizar tareas como levantar una pared y revocar -que en su complejidad superan a las que realiza el ayudante, pero no alcanzan a las del oficial-; y el oficial, que se caracteriza por tener conocimientos en la lectura de planos, saber calcular y medir distancias y ángulos, y tener la capacidad de encargarse de la dirección de una obra. Los obreros habitualmente se inician en el sector a edades tempranas, especialmente ingresando a través de otros obreros que se encuentran trabajando en distintas obras, de la bolsa de trabajo de UOCRA o, en menor medida, de alguna institución educativa que opera como nexo entre los estudiantes, egresados y los empleadores. Como han señalado investigaciones anteriores (por ejemplo, Miranda, 2012), el principal canal de inserción suele ser el de las redes de familiares y conocidos. Los técnicos y profesionales, por su parte, suelen ser reclutados a través de avisos en los diarios en los que se orientan las búsquedas específicamente hacia dichos perfiles.

Si se observa el conjunto del sector, siete de cada diez trabajadores $(97 \%$ de ellos son hombres) no finalizaron los estudios secundarios y el $80 \%$ se ubica dentro de las categorías de menor nivel de calificación ocupacional (Gráfico Nro.1).

\section{Gráfico Nro.1}

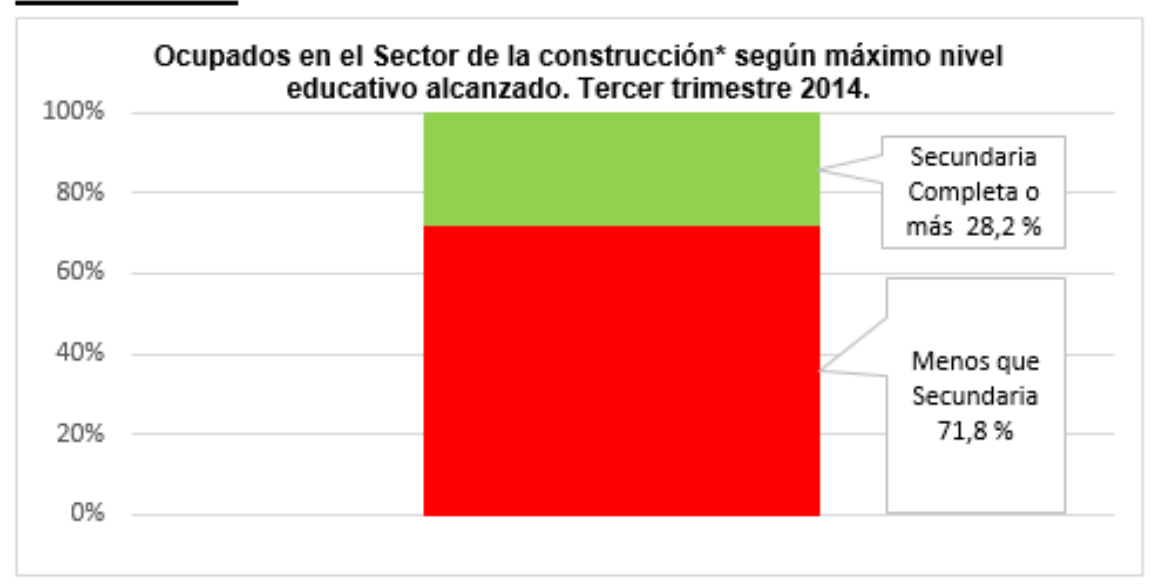

Fuente: Sosa, 2015.

${ }^{*} \mathrm{La}$ información sobre nivel educativo no pudo procesarse para jóvenes ocupados en el sector de la construcción (se procesó para el total de ocupados en el sector) debido a que el nivel de confianza de los datos excedía lo aceptable.

\subsection{Empleo joven en la construcción}

Los jóvenes de hasta 30 años ocupados en el sector representan aproximadamente un tercio de los ocupados (Gráfico Nro. 2.a). Al mismo tiempo, si se considera el total de ocupados jóvenes (entre 15 y 30 años de edad), cerca del 10\% se desempeñan en este sector (Gráfico Nro. 2.b). 
Gráfico Nro. 2 a y b

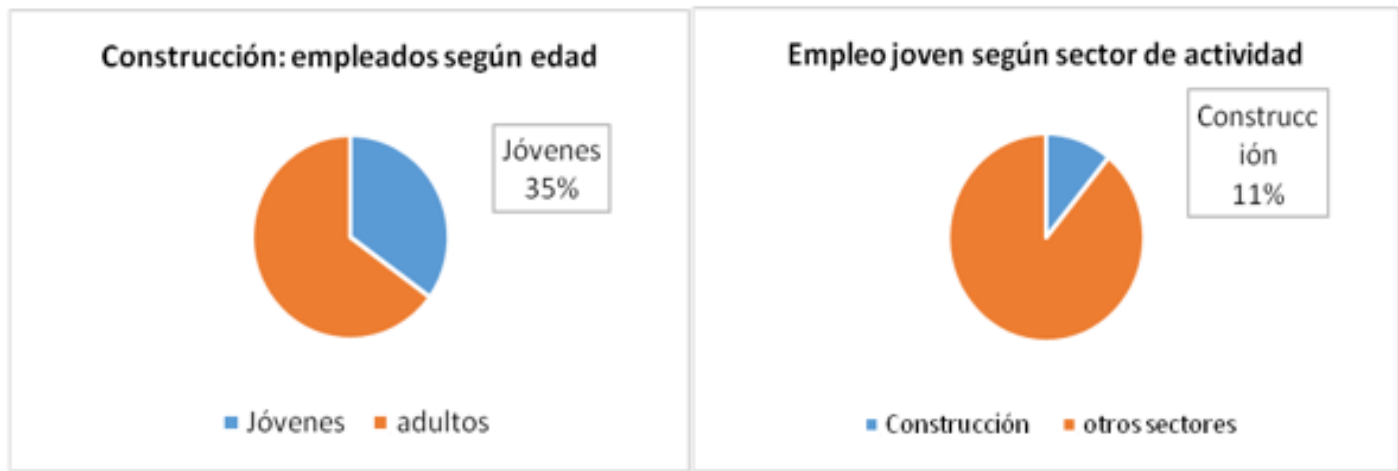

Fuente: Elaboración propia en base a EPH-INDEC 2014.

*Se consideró como jóvenes a aquellos de entre 15 y 30 años de edad.

Por su parte, la informalidad que caracteriza al sector se acentúa en el caso de los jóvenes, ya que se trata de una de las ramas de actividad con mayor índice de informalidad laboral. Por esta razón, a la vulnerabilidad laboral juvenil se le suma la vulnerabilidad propia de los ocupados del sector, manifestándose en tasas de informalidad superiores al $80 \%$ para los menores de 30 años ocupados en la construcción (Gráfico Nro.3).

\section{Gráfico Nro. 3}

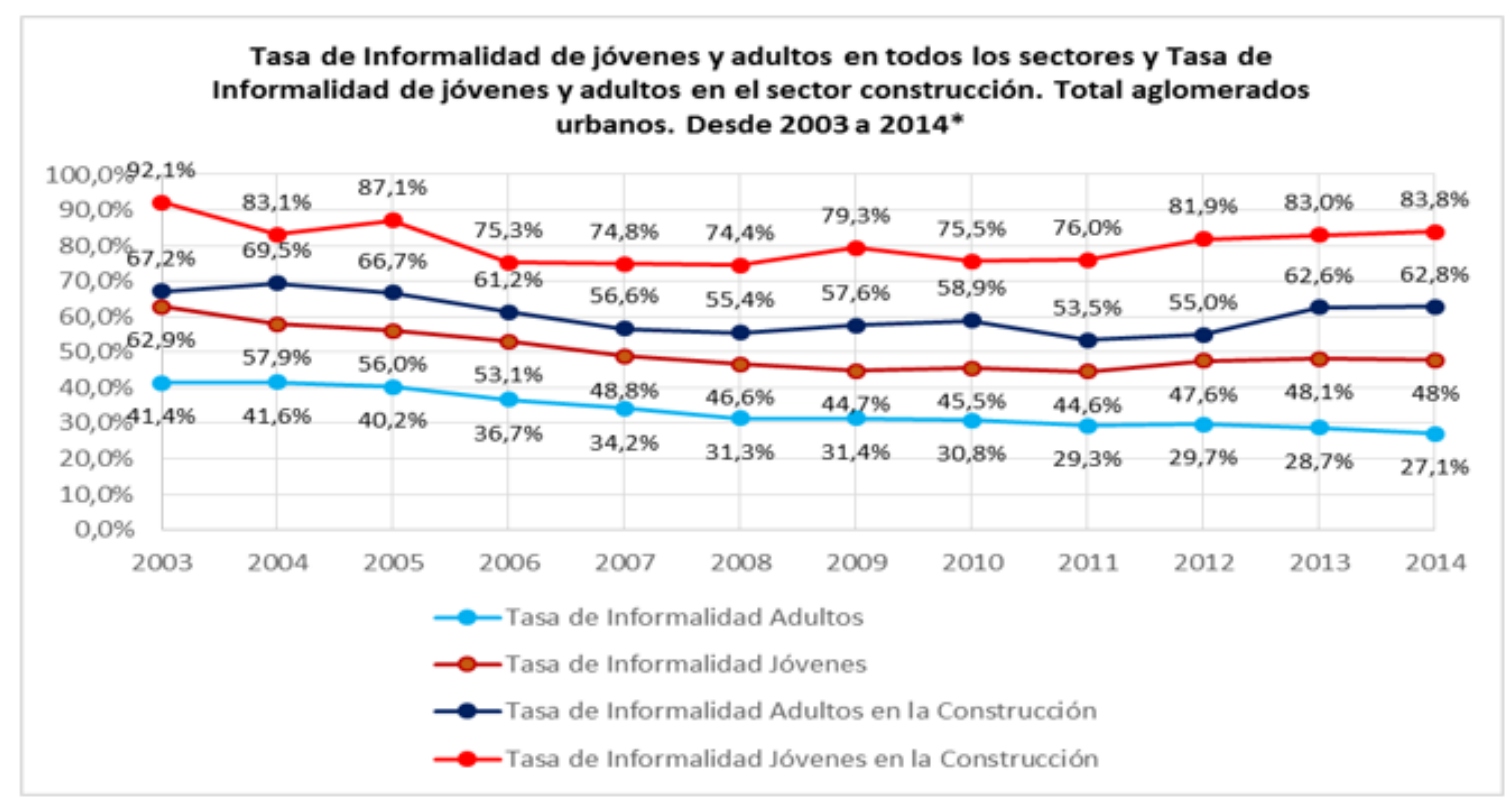

Fuente: Elaboración propia en base a EPH INDEC y Sosa, 2015.

Notas:

*Se utilizó el tercer trimestre para todos los años excepto para 2007 (4t) por no estar disponible.

** Tasa de empleo JOVEN Informal: calculada sobre el total de asalariados jóvenes ( 15 a 30 años).

Tasa de empleo ADUL TO Informal: calculada sobre el total de asalariados adultos ( 31 años o más).

Tasa de Informalidad de JOVENES en la CONSTRUCCION: calculada sobre el total de asalariados jóvenes (15 a 30 años) en el sector de la construcción.

Tasa de Informalidad de ADULTOS en la CONSTRUCCION: calculada sobre el total de asalariados adultos (31 años o más) en el sector de la construcción. 
A pesar del descenso en los niveles de informalidad ${ }^{13}$ para el conjunto de los asalariados entre los años 2003 y 2014, el significativo porcentaje de trabajadores informales en la construcción no se ha visto modificado. Es más: si se desagrega por edad y por sectores, puede observarse la persistencia de los problemas estructurales vinculados a la situación desventajosa de ciertos sectores (como la construcción) frente al resto, y la situación desventajosa del empleo joven frente al empleo adulto. Podemos sumar, en este caso, la aún más desventajosa situación de los ocupados que son jóvenes y que trabajan en la construcción, quienes actualmente tienen un nivel de informalidad que se ubica cerca del $84 \%$. Se produce así una suma de vulnerabilidades dentro del sector, ya que los jóvenes muestran niveles más altos de informalidad que en el resto de los sectores de empleo juvenil y que los adultos dentro del mismo sector. Los circuitos de acceso al empleo suelen ser informales, especialmente en el caso de los menos calificados. De este modo, el sector se caracteriza por un conjunto de condiciones estructurales adversas a la posibilidad de constituirse en una vía de acceso al empleo decente para los jóvenes.

\section{FORMACIÓN EN LA CONSTRUCCIÓN}

La formación orientada al sector incluye educación universitaria, técnica terciaria, secundaria y formación profesional. Nos centraremos en las dos últimas por el foco de este artículo. La formación de los técnicos de nivel secundario se realiza en las escuelas de educación técnica de la especialidad de "Construcciones", pudiendo obtener el título de Maestro Mayor de Obras o Técnico en Construcciones. Los perfiles de estos técnicos se dirigen a ocupar un segmento de empleos de calificación técnica, como se ha mencionado al describir el proceso de trabajo. En 2011, 11,4\% de la matrícula de la educación técnica secundaria se dirigía a la especialidad. La posibilidad que creó la Ley Nacional de Educación Técnico Profesional ( $\mathrm{N}^{\circ} 26058$ de 2005), de contar con nuevos fondos y procesos de fortalecimiento institucional, al mismo tiempo que el reconocimiento de los títulos, cambiaron las condiciones de funcionamiento de las escuelas técnicas, aunque no hay datos específicos sobre el sector al respecto. Para el caso específico de las escuelas técnicas, la Ley establece las Prácticas Profesionalizantes obligatorias para todos los alumnos de la modalidad. Son prácticas no rentadas que forman parte de la currícula y se las incorpora como requisito para la obtención del título de técnico. De modo que se propone una práctica concreta de formación en el trabajo, que podría ser puente de acceso al empleo.

La oferta pública y gratuita de FP depende de los Ministerios de Educación provinciales. Existen también centros de FP que dependen de los Municipios locales, como también ofertas de Organizaciones de la Sociedad Civil que no otorgan títulos oficiales. La política de FP está estructurada por las leyes que regulan la organización de la educación en cada provincia, encuadradas bajo la Ley Nacional de Educación Técnico-Profesional (ETP). El INET (Instituto Nacional de Educación Técnica) es quien registra a las Instituciones de FP que están habilitadas para emitir títulos y certificaciones de educación técnico-profesional. El 9\% de la matrícula correspondía a la especialidad en 2011 según

\footnotetext{
${ }^{13}$ Las tasas de informalidad fueron calculadas utilizando como variable proxy la existencia o no de aportes jubilatorios para los asalariados a partir de la encuesta permanente de hogares.
} 
fuentes del $\mathrm{INET}^{14}$.

La FP, asimismo, recibe apoyo desde el Ministerio de Trabajo, Empleo y Seguridad Social. A través de la consolidación del Sistema Nacional de Formación Continua, dicho Ministerio contribuye al fortalecimiento de instituciones educativas de FP (con asistencia técnica y financiamiento, tanto para equipamiento, como para el desarrollo de cursos específicos). Los programas de Promoción del Empleo (PJMMT, PROGRESAR, Seguro de Empleo y Capacitación, etc.) incluyen cursos de FP entre sus componentes. La formación en la construcción ha sido un componente importante en los cursos brindados por este ámbito, ya que 20\% de ellos, cerca de 800.000 trabajadores, fueron formados entre 2007 y 2013 en ese sector. Estos cursos son diseñados en base a competencias, son más cortos, y más específicos que los brindados por la FP en su versión "educativa".

Una cuestión clave para entender la formación en el sector, es la fuerza del diálogo tri-partito como instrumento de negociación no sólo de la formación sino también de las regulaciones, condiciones de trabajo y de la gestión de las calificaciones en el sector formal. La importancia de este diálogo se refleja asimismo en la gestión de la obra pública, que ha estado vinculada, como se ha visto, al dinamismo del sector en el periodo.

Más allá de esta oferta, la principal forma de capacitación de los trabajadores en el sector refiere a los procesos de formación en el propio proceso de trabajo, cruzada por la segmentación. En las empresas grandes y medianas, el ascenso de una categoría a otra se produce dentro de la obra, a través de los procesos de formación que se despliegan en el propio proceso de trabajo. Por cada 200 horas trabajadas en una actividad más compleja que aquella para la cual un trabajador fue contratado, se le debe reconocer una categoría superior. Este reconocimiento lo realizan automáticamente los subcontratistas o los delegados sindicales que están en las obras, que solicitan la categorización de los trabajadores según la cantidad de horas trabajadas y los conocimientos adquiridos. Tanto la categoría, como el segmento o unidad productiva en la que trabajan y el poseer conocimientos específicos -especialmente conocimientos en gas o electricidad- inciden en el nivel salarial.

Este proceso eventualmente deriva en nuevas categorizaciones de los obreros hasta llegar a ser oficiales, situación que a la vez puede derivar en la conformación de sus propias empresas o cuadrillas de trabajo, convirtiéndose en subcontratistas que reclutan familiares o conocidos, que a la vez son formados en el rubro ${ }^{15}$. En los cuentapropistas también se comienza el recorrido aprendiendo con otros, pero en condiciones de alta vulnerabilidad, como se ha visto.

En suma, los aprendizajes realizados en el proceso de trabajo, así como la experiencia laboral tienen una gran importancia en relación con la movilidad dentro de los puestos de trabajo del sector. Pero el dinamismo de los nuevos marcos institucionales y de financiamiento de la educación técnica en su conjunto, de la formación profesional inicial y continua, y el entramado de dispositivos de políticas sociales orientadas a la restitución de derechos, generaron un nuevo dinamismo, que se observará en los casos concretos que se

\footnotetext{
${ }^{14}$ Son números que difieren según la fuente dentro del Ministerio de Educación. Según datos del Relevamiento Anual de la DINIECE (año 2012) la proporción es aún mayor del total de alumnos que asisten al nivel, casi un $20 \%$ realiza cursos vinculados al sector de la construcción.

15 Dada la elevada rotación de trabajadores característica del sector, en ocasiones se debilita la transmisión intergeneracional de saberes específicos.
} 
examinan a continuación.

\subsection{Vinculaciones entre formación y empleo en el sector}

Tres casos fueron seleccionados para analizar las tramas de relaciones entre los actores de educación-trabajo en el sector, ya que permiten examinar segmentos diferentes en la conformación de estos mundos del trabajo de los jóvenes en la construcción, y reflexionar sobre sus alcances y tensiones.

a. La Formación Profesional en la construcción y el rol de los sindicatos: el caso del CFP UOCRA-La Matanza

El principal oferente con alcance nacional de cursos de FP lo constituye la Red de Instituciones del sindicato UOCRA ${ }^{16}$, que cuenta con 34 Centros en distintos puntos del país, conveniados con las jurisdicciones educativas provinciales y/o el Ministerio de Trabajo Nacional ${ }^{17}$. En todo el conjunto de estas instituciones se observan relaciones de importante dinamismo entre centros educativos, el sector productivo y el sector sindical.

Dentro de esta oferta, el caso elegido para comprender los circuitos específicos que se configuran entre este tipo de oferta educativa y el empleo en el sector de la construcción es el del CFP N ${ }^{\circ}$ 403, perteneciente al Municipio de La Matanza. Dicho centro dicta cursos regulares vinculados a la construcción, con un nivel de calificación operativa, en convenio con el Ministerio de Educación de la Provincia de Buenos Aires. Se asienta en dependencias del mismo Municipio y percibe financiamiento de diversas agencias gubernamentales: 1) sus salarios docentes son financiados por el Ministerio provincial y además recibe financiamiento para equipamientos, becas y capacitación docente del INET (Ministerio de Educación Nacional); 2) bajo acuerdos específicos recibe financiamiento para insumos y el desarrollo de cursos por parte del Ministerio de Trabajo; 3) a partir de acuerdos entre la Fundación UOCRA y empresas particulares vinculadas al sector de la construcción recibe equipamiento, insumos y otras donaciones.

El Centro ofrece cursos de 200 horas certificados por el Ministerio provincial y el Sindicato, así como también cursos más cortos, de 40 horas, con certificación del Ministerio de Trabajo. El requisito de ingreso a los cursos es la primaria completa. Participa regularmente de la Mesa Regional del COPRET de La Matanza (Consejo para la Educación y el Trabajo), que aglutina referentes de escuelas técnicas, cámaras empresarias, sindicatos, el Instituto Municipal para el Desarrollo Económico y Social, la oficina de empleo de la zona (que depende del Ministerio de Trabajo Nacional) y una Universidad regional

\footnotetext{
${ }^{16}$ La Fundación UOCRA no sólo gerencia la Red de Instituciones de FP sino que también incluye escuelas de jóvenes y adultos de primaria y secundaria, y terciaria técnica. También regula los contenidos de los cursos en diálogo con los Ministerios de Educación y con el INET. Asimismo, realiza convenios con el Ministerio de Trabajo para ofrecer cursos de formación específicos para los trabajadores ya insertos, y para los beneficiarios de programas de promoción del empleo, como así también programas de Certificación de Competencias Laborales para los trabajadores. En este sentido, la estrategia apunta a ofrecer un pool de alternativas para las personas que se acercan demandando formación (en muchos casos jóvenes) y para los trabajadores, dialogando al mismo tiempo con los dos Ministerios (de Educación y de Trabajo) que regulan esta oferta.

${ }^{17} \mathrm{La}$ oferta sindical se completa con otros sindicatos que ofrecen cursos de la familia profesional vinculada a la construcción (como el SUTERH -Sindicato Único de Trabajadores de Edificios de Renta y Horizontal-).
} 
(Universidad Nacional de La Matanza). En las reuniones de la Mesa se evalúa la pertinencia de la oferta de cursos, las demandas de formación, la apertura de nuevos centros y proyectos de articulación con empresas a través del instrumento del "crédito fiscal".

El Centro presenta una historia vinculada a la contención social. Se funda a mediados de los noventa y amplía su matrícula a comienzos de los dos mil, en un contexto de amplia desocupación. Sus cursos eran solicitados por una población de trabajadores que habían perdido sus empleos y buscaban adquirir formación como estrategia de reinserción laboral. Actualmente, el público que asiste al centro proviene de sectores medio-bajos, con un porcentaje de alrededor del $40 \%$ de alumnos jóvenes, con o sin secundaria, en muchos casos con experiencia de trabajo en la construcción. También participan de los cursos beneficiarios de programas de promoción del empleo.

Desde la visión de su Director, la FP tiene cierta flexibilidad en la organización de sus cursos, característica que le permite responder a demandas concretas que surgen de determinadas vinculaciones. En este sentido, el entramado local supone otras relaciones institucionales que se suman y contribuyen a generar oportunidades de inserción laboral en sus alumnos y egresados.

En relación a las vinculaciones con el sistema educativo, la participación en reuniones de la mesa regional del COPRET fue motor para la vinculación con escuelas técnicas secundarias (ofreciendo a los alumnos de esa institución cursos específicos), así como también vinculaciones con la Educación de Jóvenes y Adultos, generando un título secundario para adultos con orientación en electricidad.

En relación a las vinculaciones con el sistema productivo, son múltiples las articulaciones. En primer lugar, el CFP 403 recibe beneficiarios de programas de promoción del empleo, a partir del vínculo con la Oficina de Empleo regional, donde también derivan egresados para las búsquedas laborales. Por su parte, como las empresas participan a través de sus cámaras empresarias en las reuniones del COPRET, pueden plantear allí demandas de formación que recaen en el centro, y lo mismo ocurre de parte de cooperativas de trabajo vinculadas al Municipio. Además, el Centro se vincula al mismo sindicato de la construcción (UOCRA) quien cuenta con bolsas de trabajo para el sector en sus seccionales regionales. La Fundación UOCRA, a través de su estrategia de orientación profesional, informa a alumnos y egresados sobre las acciones de las seccionales regionales, contribuyendo a socializar en torno a los circuitos de acceso a empleos. Muchas empresas constructoras contratistas y sub-contratistas solicitan trabajadores en las bolsas de trabajo del sindicato (generalmente los empleos ofrecidos bajo esta modalidad son formales), y en ocasiones son alumnos o egresados de los centros de FP quienes acceden a dichos puestos.

De este modo, en el diseño institucional de esa oferta educativa, se sugiere la potencialidad de un vínculo directo entre el aula y el mercado de empleo, mediado por las acciones del sindicato. Sin embargo, este circuito no se encuentra institucionalizado, sino que son los mismos cursantes o egresados quienes recorren el camino de una institución a otra. Los mecanismos de articulación institucional, por tanto, dependen de la voluntad y búsqueda propia de información de parte de los jóvenes, para orientar su inserción laboral.

Existe un tipo de vinculación institucionalizada con empresas del sector, que de acuerdo a la visión del Director del Centro, resulta en un vínculo directo con el sector empresarial. Se trata de determinadas empresas específicas que producen insumos para la construcción. Estas empresas (por ejemplo de cerámicos, yeso, cemento, pegamentos), a 
través del crédito fiscal, equipan al centro y ofrecen cursos de actualización sobre sus productos, tanto para alumnos como para docentes de los centros. Esta trama resulta importante en relación a su "ida y vuelta": las empresas aprovechan para promocionar sus productos al mismo tiempo que alumnos y docentes del centro se benefician con actualización permanente y equipamiento. Además, esta trama significa para los cursantes un beneficio en su inserción como cuentapropistas, ya que les permite ampliar sus conocimientos sobre el uso y colocación de determinados productos del mercado.

De acuerdo a una entrevista realizada con un gerente de una empresa de pastina para la colocación de cerámicos, los acuerdos entre empresas y la Red de instituciones de la Fundación UOCRA contribuyen principalmente a la actualización de contenidos curriculares de los centros (a través de la elaboración de manuales y otros contenidos de formación) que redunda en la mejor calidad de la enseñanza. No obstante, las empresas proveedoras de insumos no son espacios de inserción laboral para los egresados.

Asimismo, una articulación institucionalizada se reconoce en el apoyo de la oficina de empleo regional a través de subsidios al desarrollo de emprendimientos (pequeñas empresas de construcción y mantenimiento). El centro capacita a estos alumnos, que luego reciben subsidios para la compra de sus propias herramientas y la puesta en marcha de pequeños emprendimientos.

Puede evidenciarse, por lo tanto, que la estrategia del Centro apunta a generar mayores oportunidades de inserción en el empleo a trabajadores desocupados, como así también a profesionalizar su recorrido laboral, en el caso de los que ya están trabajando en el sector. Por un lado, se establecen acuerdos con empresas, así como también con cooperativas de trabajo, que requieren de capacitaciones cortas y puntuales para sus trabajadores (generalmente desarrolladas a partir de acuerdos con el Ministerio de Trabajo) y que apuntan a profesionalizar el trabajo, dentro del empleo formal en el sector. Por otro lado, se apunta a ofrecer recorridos formativos a trabajadores y desocupados, con el fin de brindar una herramienta que se considera valiosa en la carrera profesional. El esfuerzo del Centro está dado en que los cursantes puedan incorporar información sobre los derechos laborales y valorizar el empleo formal. Asimismo, procuran que se reconozca el valor de sus saberes y que puedan profesionalizar sus actividades (que en muchas ocasiones se realizan como actividad cuentapropista).

Sin embargo, no puede sostenerse que esta trama contribuya a ampliar las posibilidades de inserción en el empleo formal (algo difícil, de todos modos, por las características mismas del sector). Pero, a pesar de ello, desde las voces de los entrevistados se identifica el valor de estos aprendizajes en términos subjetivos para los cursantes: en la conformación de una identidad laboral, en el valor de lo que implica la obtención de un empleo, en el conocimiento sobre los derechos laborales y en la profesionalización. Estos aprendizajes pueden significar un recurso significativo en la configuración de la propia trayectoria laboral.

\section{b. La escuela técnica, las pasantías y el sector de la construcción}

El segundo caso a analizar es el de establecimientos de educación técnica de nivel secundario que cuentan con un sistema de pasantías o prácticas profesionalizantes vinculadas al sector de la construcción y que apuntan a vincular a los jóvenes con empleos en puestos de trabajo calificados. 
En la provincia de Buenos Aires, las prácticas obligatorias para alumnos de secundaria técnica se inician en el año 2013 (Resolución $\mathrm{N}^{\circ} 112$ ), como parte de la adecuación requerida en la Ley de ETP, ya mencionada. Las prácticas son definidas como estrategias formativas que se orientan a la consolidación y ampliación de saberes adquiridos en otros campos formativos, a través de la articulación teórico-práctica y del acercamiento de los estudiantes al mundo del trabajo y de la producción. Son de carácter obligatorio, y el tiempo y la organización de las mismas se ajusta al tipo de práctica y a cada proyecto particular $^{18}$. El cambio de paradigma entre el anterior sistema de pasantías (extracurriculares y para unos pocos alumnos y que se seleccionaban principalmente en base a sus méritos académicos) y este nuevo régimen de prácticas profesionalizantes obligatorias, curriculares y universales, supuso una profunda transformación en la concepción del lugar que las prácticas laborales ocupan en la formación secundaria técnica, y como consecuencia, en las articulaciones entre el mundo de la educación y el sector productivo. Del mismo modo, en este esquema, los actores estatales se ven necesariamente más involucrados en el desarrollo de los programas.

En la Ciudad de Buenos Aires, en cambio, las prácticas obligatorias no han sido aún reglamentadas. Las escuelas técnicas que cuentan con pasantías, las realizan a través de un programa especial dependiente de la Gerencia Operativa de Educación y Trabajo, llamado Aprender Trabajando ${ }^{19}$, que regula el dispositivo mediante el Decreto $\mathrm{N}^{\circ} 1374^{20}$. La mayor parte de los proyectos que se desarrollan actualmente son de escuelas secundarias técnicas. Se contempla la posibilidad de realizar una "Práctica educativo laboral productiva" (estancia en una unidad productiva en la que el alumno/pasante tenga contacto con el proceso de producción de bienes) o una "Práctica educativo laboral de servicios" (proyectos que implican la prestación de un servicio para un ente externo, siempre en vinculación con los objetivos curriculares). La selección de los beneficiarios queda a criterio de las escuelas y las unidades productivas.

Debido a las características propias del sector, los sistemas de formación a través de pasantías o prácticas profesionalizantes de nivel secundario, no son frecuentes. La construcción supone ciertos riesgos al momento de tener a jóvenes estudiantes en la obra, por la actividad en sí misma, principalmente. Por otra parte, los modos de transmisión de los saberes de los oficios habitualmente se realizan de modo intergeneracional, resultando poco frecuente encontrar otros mecanismos de aprendizaje que no estén ligados a la idea

\footnotetext{
${ }^{18}$ Los formatos de prácticas que se prevé son: Proyectos productivos externos, que se realizan en empresas, organismos estatales o privados o en organizaciones no gubernamentales; Proyectos tecnológicos orientados a la investigación, experimentación y desarrollo de procedimientos, bienes o servicios relevantes desde el punto de vista social y que introduzcan alguna mejora dentro de los existentes; Proyectos de extensión diseñados y organizados en la institución educativa, para satisfacer necesidades comunitarias. El circuito de puesta en funcionamiento de las prácticas determina que los directivos de escuelas, los empresarios locales, los funcionarios municipales y las organizaciones de la sociedad civil de cada localidad tengan que entrar en contacto para armar los proyectos que sustentarán cada iniciativa.

${ }^{19}$ El Programa ofrece el marco legal (convenios entre instituciones, contratos para los pasantes), el pago de módulos para los tutores pedagógicos de los establecimientos educativos (solo de nivel secundario, ya que en los restantes niveles no está contemplado), y el pago de una asignación estímulo para los alumnos beneficiarios que realizan las prácticas en instituciones públicas. En el caso de aquellos vinculados a empresas privadas, es la misma empresa quién paga la asignación.

${ }^{20}$ En el año 2013 se presentaron 415 proyectos en el marco del Programa Aprender Trabajando. Entre ellos fueron aprobados 411, en 136 instituciones educativas. Ello implicó una cantidad de 2846 practicantes. El 80\% de los proyectos se realizan con organismos públicos y el restante 20\% con privados (Informe de Gestión 2013. Programa Aprender Trabajando, Gerencia de Educación y Trabajo- GCABA).
} 
del ayudante/aprendiz de obra. Finalmente, los modos de contratación, marcados muchas veces por la informalidad, sobre todo en los escalafones más bajos en la jerarquía de trabajadores, dejan poco espacio para otros tipos de vínculo laboral.

En la provincia de Buenos Aires, frente a la implementación de las prácticas obligatorias, las escuelas técnicas con la modalidad de construcciones tuvieron el desafío de elaborar proyectos para cumplir la norma, ya que la posibilidad de asociarse a empresas constructoras privadas era casi inexistente. En este marco, se encontraron dos salidas al problema: por un lado, muchas escuelas conveniaron con los gobiernos locales para la realización de tareas de mantenimiento y puesta en valor de los edificios municipales; por otro lado, se elaboraron proyectos similares al interior de las mismas escuelas. El grado de adecuación de las actividades al desarrollo de aprendizajes técnicos de la especialidad fue de diversa intensidad según cada caso. Sin embargo, más allá de los saberes desplegados, es posible decir que específicamente para los alumnos de la especialidad de construcciones, el desarrollo de dichas prácticas y el cambio de paradigma en su organización, no parece haber acrecentado sus oportunidades de vincularse al mundo del trabajo formal, como sí ha sido el caso en otras especialidades. Si en otros sectores de actividad la escuela ha podido funcionar como una suerte de puente facilitador del acceso a empleos en un segmento del mercado de mayor formalidad, aquí el rol de la escuela queda un poco más difuso: el dispositivo de prácticas pareciera no haber tenido el mismo desarrollo en cuanto a sus posibilidades de insertar a los jóvenes en el sector posteriormente. De todos modos, los convenios con gobiernos locales y las prácticas realizadas en las mismas escuelas se constituyen en instancias de aprendizaje y experiencias valiosas para los jóvenes.

Si bien afirmamos que el dispositivo de prácticas no resulta el mecanismo más efectivo para tender puentes con el empleo formal para los jóvenes técnicos en el sector de la construcción, existen algunas experiencias de vinculación entre escuelas técnicas y organismos productivos que merecen ser observadas. Dichas experiencias ilustran, aunque a una escala limitada, nuevos entramados de actores e instituciones que pueden contribuir al acercamiento al mundo del trabajo en el sector, y nos permiten pensar en una de las hipótesis de las cuales partía este trabajo acerca de que frente a la complejidad del escenario, algunos circuitos de educación-formación-empleo realizan esfuerzos por fortalecer sus vínculos, por ampliar sus redes, "entramándose" más fuertemente y más diversamente con el mundo del trabajo.

Tal es el caso de la Escuela Técnica Otto Krausse que trabaja con Infraestructura Escolar (IE) en la Ciudad de Buenos Aires para la realización de prácticas, pero tiene muchos otros vínculos con actores del mundo de la construcción. Esta escuela está ubicada en el barrio de San Telmo de la Capital Federal, y ofrece la modalidad de Construcciones, entre otras. Actualmente, recibe una población muy heterogénea en términos socioeconómicos. En el marco del Programa Aprender Trabajando, la escuela junto con la oficina de IE (dependiente del Ministerio de Educación local) ideó en 2013 un proyecto de prácticas que involucrara a los alumnos de 5 to año repitentes, con el fin de reinsertarlos en el grupo social de la escuela y motivarlos para continuar sus estudios en la institución. La propuesta funcionó con mucho éxito en esa oportunidad y se decidió replicarla en 2014. Algunos estudiantes realizaron una práctica rentada en el Ministerio de Educación (la mitad de ellos en IE y la otra mitad en una oficina que oficia de contralor en las tareas de Infraestructura), mientras que otros hicieron su pasantía en la misma escuela, diseñando, renovando y construyendo espacios comunes del edificio. Anteriormente habían realizado 
experiencias similares con empresas privadas, aunque las tareas que los jóvenes realizaban no se adecuaban a los aprendizajes en la especialidad.

En la escuela, como en el caso del CFP descripto anteriormente, existen otras vinculaciones con empresas, para la realización de capacitaciones a docentes y alumnos en diversos procesos de trabajo, visitas a las empresas y obras, que tienen lugar periódicamente en el marco de la formación técnica que se ofrece. También mantienen vínculos con la UOCRA y la Cámara de la Construcción, quienes ofrecen capacitaciones y el acceso a algunas obras.

Así, a partir de la creencia de que la inserción en el mundo del trabajo es un proceso complejo aún para los jóvenes técnicos con secundario completo, se van impulsando una multiplicidad de interacciones institucionales. Por ejemplo, como parte de sus estrategias de apoyo, derivan a CFP a aquellos alumnos que son ayudantes en la construcción, a los que les resultan sencillas las materias prácticas de taller, pero tienen problemas para mantener el ritmo que exige una escuela técnica. Ante la deserción escolar de estos chicos, la escuela les facilita la derivación para que puedan acreditar sus saberes en oficios y tener una credencial al momento de su inserción laboral.

En relación con la inserción laboral posterior al egreso, los referentes del Departamento de Construcciones calculan que ronda entre el 80 y 90\%. Si bien no es mediante el dispositivo de prácticas, la escuela actúa muchas veces de mediadora para la obtención de empleos, ya que reciben pedidos de jóvenes técnicos capacitados por parte de empresas del sector. En general, son trabajos que permiten sostener estudios superiores, ya que la mayoría de los jóvenes continúa carreras universitarias (arquitectura, 50\%; e ingeniería $30 \%$, principalmente).

En resumen, en el marco de las prácticas profesionalizantes no existen intervenciones específicas para la inserción laboral efectiva, ya que son exclusivamente educativas. A pesar de responder a distintos paradigmas y tener diferente estatus legal, esto es algo compartido por las experiencias de la Provincia y de la Ciudad de Buenos Aires. Si bien algunos (pocos) jóvenes pueden quedar como empleados en los organismos receptores, no es lo más frecuente en las empresas de la construcción. Sin embargo, algunas escuelas, las más activas, han desarrollado tramas vinculantes con empresas y otros actores significativos del mundo laboral, y cuentan con bolsas de trabajo y charlas de orientación, que ayudan a obtener herramientas valiosas. Analizando las distintas experiencias, reforzamos la idea de que las principales dificultades para la inserción posterior de los jóvenes en las empresas están dadas por las condiciones del sector: escasa rotación de personal, contrataciones informales, tercerización por parte de empresas subcontratistas, alta inestabilidad. Son las mismas limitaciones que encuentran las escuelas para conveniar con las empresas para el desarrollo de las prácticas.

c. El caso de una escuela secundaria con orientación en economía social: la construcción natural como ampliación de los horizontes del mundo del trabajo

Otra forma en que aparece la vinculación entre formación y trabajo en el sector, se enmarca en la perspectiva de la economía social, apuntando al segmento del auto-empleo y del trabajo cooperativo. Aquí encontramos un caso de educación secundaria, pero con una 
orientación novedosa y bien diferente de la que analizamos en el apartado anterior. Se trata de una escuela secundaria de la provincia de Neuquén ${ }^{21}$, que ofrece un bachillerato con orientación en Economía Social y Prácticas de Emprendimientos. Allí se brindan dos certificaciones conjuntas (los estudiantes realizan todo el recorrido de manera articulada): el de Bachiller, expedido por la dirección de Educación Media del Consejo Provincial de Educación, y una certificación por 1805 horas que expide la Dirección de Adultos del CPE según la orientación correspondiente (Diseños Constructivos, Informática, Gastronomía y Agropecuaria). La orientación en economía social atraviesa toda la formación, por medio de materias específicas y del impulso de ciertas prácticas institucionales orientadas al desarrollo de valores como la solidaridad, la equidad, el precio justo, el cooperativismo, el emprendedorismo y el asociativismo. La formación para el trabajo se estructura, por un lado, a partir de la capacitación en talleres y de la realización de emprendimientos productivos; y por otro lado, de la participación en prácticas educativas.

En el marco del taller de Diseños Constructivos, los jóvenes reciben formación orientada al sector de la construcción. Específicamente, son capacitados en técnicas de construcción natural y reciben una formación más amplia en principios de permacultura ${ }^{22}$. Inicialmente, esta formación tenía como fin la autoconstrucción: estas técnicas eran una herramienta considerada como alternativa para que los jóvenes mejoraran las situaciones habitacionales de sus familias, o bien para la construcción de hornos o estufas, entre otras posibilidades. Sin embargo, actualmente se concibe esta formación como una alternativa de inserción laboral para estudiantes y egresados.

Los componentes educativos de esta trama se completan con las capacitaciones puntuales que miembros del CIDEP ${ }^{23}$-Centro de Investigación, Desarrollo y Enseñanza de Permacultura- dieron tanto a docentes como a estudiantes durante algunos años y con cursos cortos dictados en la institución por la FACIAS -Facultad de Ciencias del Ambiente y de la Salud- de la Universidad Nacional del Comahue sobre energías renovables. Tanto los cursos dictados por el CIDEP como por la FACIAS fueron financiados por el programa de crédito fiscal impulsado por el INET.

Además, en los casos en que estudiantes de la escuela se interesan especialmente en las técnicas de construcción natural, la institución gestiona prácticas educativas para que profundicen los conocimientos adquiridos. En este marco, algunos jóvenes han participado en calidad de pasantes en la construcción en tierra cruda de un salón comunitario de una ONG de la ciudad, así como en obras de viviendas particulares.

Respecto de la construcción natural como campo de inserción laboral, hay jóvenes de la escuela -estudiantes y egresados- que son recomendados y/o contratados por profesores de la institución para trabajar en obras de viviendas particulares ${ }^{24}$. La dinámica usual de trabajo, vinculada a la economía social, implica el trabajo colaborativo en las denominadas "mingas": personas con vasta experiencia en el tema y otras en formación comparten jornadas de trabajo en las que, si bien se suele pagar monetariamente a los

\footnotetext{
${ }^{21}$ La escuela Nuestra Señora de la Guardia recibe 260 estudiantes provenientes de hogares de bajos recursos materiales. Se brinda el nombre por pedido expreso de la institución.

${ }^{22}$ La permacultura es entendida como "el diseño de asentamientos humanos sostenibles y sustentables" (Morrow, 2010: 13), articula conocimientos de la sabiduría tradicional y de la ciencia moderna.

${ }^{23}$ Es un centro de permacultores que investiga, desarrolla y capacita en diversas técnicas para el desarrollo de formas de vida sustentables ubicado en El Bolsón, provincia de Río Negro.

24 Ciertamente, en la zona la construcción natural es utilizada casi exclusivamente en obras de viviendas particulares.
} 
trabajadores, la ganancia económica no es el objetivo primordial, sino se estructura a partir de la colaboración con la persona a la cual se le construye, por ejemplo, la vivienda.

En estos casos, se suele trabajar para obras puntuales, durante el periodo de tiempo que dura la obra y en condiciones informales de contratación. Esta falta de continuidad en la contratación se vincula a las propias dinámicas del sector, así como a la escasez de obras en la zona, como consecuencia de ser técnicas que -a pesar de que históricamente se han utilizado para construir viviendas- recién en los últimos años han comenzado a popularizarse y a ser consideradas como una opción para la construcción de viviendas urbanas. En este sentido, la precariedad que suele caracterizar las formas de contratación en el sector de la construcción en general -informalidad y temporalidad- aparece en la construcción natural, del mismo modo en que puede verse en la construcción tradicional.

Como también se ha visto en el caso del CFP, desde el cuerpo docente se resaltan los aprendizajes de la formación impartida, en este caso vinculados a aspectos cooperativos y creativos presentes en el proceso de trabajo que se asocian a estas prácticas. Desde la visión de los jóvenes, algunas veces se rescata la formación recibida y las experiencias desarrolladas como positivas, resaltando las posibilidades de autoconstrucción que brinda y la creatividad en el proceso de trabajo, mientras que otras veces se plantean continuidades con la precariedad que asume el trabajo en el sector y valoran negativamente la formación en construcción natural recibida.

La trama mencionada implica distintos tipos de financiamiento para equipamientos, materiales, salarios y capacitaciones docentes. Asimismo, los emprendimientos productivos que se realizan en el taller, cuando son rentados, permiten financiar parcialmente gastos del propio taller, así como los viajes de estudio de los jóvenes. No obstante, los entramados que se establecen son esporádicos o débiles (a diferencia de los entramados más institucionalizados, por ejemplo, del CFP): la realización de cursos cortos está ligada a la obtención de recursos (vía INET), así como de los contactos personales de los profesores. Las prácticas educativas en el área también dependen de los contactos de los docentes y varían año a año (en parte, porque estas prácticas, a diferencia del caso de las prácticas profesionalizantes en la Provincia de Buenos Aires, no son recorridos estandarizados que se repiten año a año, sino que son a demanda, en función de los intereses de los jóvenes). Por otra parte, la lógica de trabajo de la construcción natural asociada a la economía social no suele cristalizarse en empresas privadas, por lo que en lugar de analizar si se establecen vínculos con empresas privadas, debemos analizar las vinculaciones que sí suelen establecerse con algunas OSC, principalmente sin fines de lucro. Sin embargo, en la trama analizada, estas vinculaciones también son débiles.

Finalmente, cabe destacar que la experiencia ofrece capacitación para el trabajo no sólo a través del dispositivo de formación en construcciones y específicamente en construcción natural, sino que todo el enfoque institucional resignifica el valor del trabajo como dispositivo formativo. Los jóvenes egresados en algunos casos logran insertarse en empleos a través de la acción de la institución: algunos quedan trabajando en las instituciones donde hicieron pasantías o profesores reclutan jóvenes para trabajar; otros continúan con los emprendimientos productivos que iniciaron en la escuela (en grupo, solos o con familiares); algunos acceden a créditos de apoyo de emprendedores. Sin embargo, la inserción laboral en el sector es precaria, inestable e informal, pese a que se valora positivamente que los estudiantes tienen una oportunidad de experimentar el trabajo cooperativo y de comprender el enfoque de la economía social. 


\section{CONCLUSIONES}

A modo de conclusión, es posible retomar las hipótesis de trabajo inicialmente presentadas. Respecto a la primera, a pesar de que el sector entre 2003-2014 (aunque especialmente entre 2003 y 2007) ha sido central en la reactivación económica y ha adquirido un dinamismo impulsado por la obra pública, la alta informalidad persiste y se desarrollan nuevas heterogeneidades. En consonancia, la inserción laboral de los jóvenes en el sector de la construcción sigue manteniendo parámetros persistentes de alta informalidad. A ello contribuye también el hecho de que casi la totalidad de los trabajadores son varones con un nivel educativo bajo (aunque en los últimos años ha aumentado la cantidad de trabajadores que han finalizado sus estudios secundarios). Ellos suelen ingresar al sector a través de redes familiares, y el aprendizaje en el propio trabajo tiene un rol clave para los puestos de bajos niveles de calificación del sector. Estas características acotan los límites de intervención de los dispositivos educativos y formativos.

Respecto a la segunda, puede decirse que, producto especialmente del contexto laboral favorable en cuanto a la creación de empleo y de las políticas públicas de formación y empleo, se desarrolló, en el periodo, una multiplicación y diversificación de la oferta de formación vinculada al sector de la construcción. Los dispositivos dentro de esta oferta cuentan con numerosos puentes entre ellos, creando incluso interacciones entre formación profesional inicial y continua, educación técnica, educación de jóvenes y adultos, educación secundaria en contextos de pobreza y programas sociales de promoción del empleo. Las tramas fortalecieron el rol tanto de los centros como de las escuelas, como puertas de entrada a habilitar recorridos formativos en los jóvenes. Sin embargo, las políticas también muestran sus límites en cierto paralelismo de larga data entre las políticas educativas y las de empleo y, muchas veces, los lineamientos de las políticas no crean las condiciones necesarias para su adecuada implementación y seguimiento. Tampoco se incorporan suficientemente herramientas para manejar sus propios negocios, siendo esa una de las salidas laborales más frecuentes.

Respecto a la tercera hipótesis, el análisis de casos muestra que algunos circuitos de educación-formación-empleo fortalecieron sus vínculos desde múltiples tramas verticales y horizontales. En las tramas concretas que se evidencian entre las instituciones formativas y los actores del sector de la construcción, se observa la incidencia de las redefiniciones de las políticas públicas. Además de la formación especializada según el nivel, en la formación profesional sindical se habilitan procesos de profesionalización, de formación continua y acceso al conocimiento sobre los derechos laborales. Las prácticas en lugares de trabajo (especialmente públicos) de estudiantes secundarios, aportan la oportunidad de formación en el propio trabajo. Por su parte, las experiencias de economía social impulsan aprendizajes en valores cooperativos y prácticas solidarias que al mismo tiempo otorgan saberes y competencias en la especialidad. En este sentido, el esfuerzo de las articulaciones se observa en todos los casos examinados.

Sin embargo, existen evidentes distancias entre las tramas de "formación" y las de los circuitos laborales/aprendizajes en los trabajos. Por ejemplo, las particularidades del sector -en términos de estabilidad, riesgo de accidentes, precariedades de las condiciones de trabajo- se refleja en que no sea posible (o sea extremadamente dificultoso) colocar pasantes de la escuela técnica en las obras. O, cuando se produce esa colocación, se los 
margina a tareas que carecen de la riqueza formativa que podría tener la actividad. Al mismo tiempo, la formación profesional sindical se enmarca en un conjunto de esfuerzos para alcanzar mayor nivel de trabajo protegido, a través de acuerdos con empresas y cooperativas. Si bien es evidente la fortaleza del actor sindical para favorecer esta estrategia, encuentra sus límites en las condiciones laborales que priman en el sector. En este marco, una parte de sus cursantes se orienta al auto-empleo, actividad que generalmente se realiza en condiciones de informalidad.

Estas limitaciones muestran lo dificultoso que resulta ser el vínculo entre espacios educativos y empresas y el mundo laboral privado. Por una parte, se han resaltado algunos vínculos como el rol de las empresas proveedoras de insumos para la construcción, que, desde una estrategia de promoción y venta de sus productos, contribuyen a actualizar contenidos de formación. En este caso, la relación empresa-CFP es beneficiosa para la calidad educativa (en el sentido de la actualización), a pesar de que parte de una estrategia de marketing empresarial. Pero en general, entre los actores entrevistados, prima una visión crítica respecto a las vinculaciones entre las instituciones educativas y formativas, y el mundo empresarial.

Desde el mundo educativo, esta situación es visualizada como un problema, ya que la experiencia real de trabajo es considerada un aspecto central en los procesos de formación de los estudiantes, pudiendo esto operar como un puente con el empleo de calidad. Desde el mundo empresarial, algunas veces se manifiesta que no acostumbran a buscar trabajadores en instituciones educativas porque no conocen los mecanismos para incorporar pasantes y/o por los riesgos laborales que se corren, pero que les "interesaría". Podría sostenerse, entonces, que se evidencian lógicas diferentes: la de las políticas de educación y formación profesional, que promueven la articulación de los dispositivos con el mundo laboral; y la de la selección de personal y las propias estrategias de búsqueda de las empresas, en un sector donde se privilegia la experiencia del trabajador más que la certificación (Belmes, 2013).

Más allá de su contribución o no al acceso al empleo decente, directores y actores referentes de los tres casos coinciden en el valor positivo de los dispositivos. Esta "ganancia" para los sujetos está identificada en aspectos subjetivos (mayor autonomía, empoderamiento, identidad laboral, revalorización del trabajo, etc.), y en otros aspectos más amplios de las vidas de los jóvenes (que una mirada centrada en indicadores laborales no podría observar). Los modos de intervención que se observan en este sentido incluyen la orientación socio-laboral (por ejemplo en las prácticas profesionalizantes); el fortalecimiento de los saberes acerca de los derechos educativos y laborales (evidente en la FP sindical); la ampliación de las concepciones tradicionales del mundo del trabajo hacia la economía informal (especialmente en la experiencia de escuela secundaria alternativa examinada). En todos los casos puede decirse que el dispositivo de formación específico se inserta en un conjunto más amplio de estrategias de formación para el trabajo, que inciden finalmente en los resultados de aprendizaje. Estos valores positivos contrastan con un escenario de alta informalidad y heterogeneidad del sector, por el cual el acceso posterior de los jóvenes hacia empleos con todas las protecciones sociales se vuelve dificultoso.

Ahora bien, no debe perderse de vista que tanto la formación profesional educativa como la educación secundaria general y técnica, están orientadas a la formación de los estudiantes, y no a su inserción laboral. Y en este sentido es que, incluso asumiendo que se trata de un escenario difícil, las articulaciones recientes muestran un dinamismo apoyado 
por las políticas públicas que evidencia esfuerzos en la creación de oportunidades educativas y de inserción laboral de los jóvenes en un sector relevante como el de la construcción.

BUENOS AIRES (ARGENTINA), DICIEMBRE 2015

RECIBIDO: DICIEMBRE 2015

ACEPTADO: MARZO 2016

\section{REFERENCIAS BIBLIOGRÁFICAS}

BERTRANOU FABIO, RAÚL ET AL. (2011). Informalidad laboral en la provincia de Mendoza. Buenos Aires: Oficina de País de la OIT para la Argentina.

BELMES, ARMANDO. (2013). Organizaciones del mundo del trabajo y formación profesional en la Ciudad Autónoma de Buenos Aires. Buenos Aires: Ministerio de Educación C.A.B.A.

CENDA (Centro de Estudios para el Desarrollo Argentino) (2010). La anatomía del nuevo patrón de crecimiento y la encrucijada actual. La economía argentina en el período 2002-2010.Buenos Aires: Cara o Ceca.

DUBAR, CLAUDE. (2001). "La construction sociale de l'insertion professionnelle". Education et Sociétés, $\mathrm{N}^{\circ} 7$.

DURSI, CAROLINA Y ALENKA, MEREÑUK (2011). "Procesos de subjetivación en el pasaje por modalidades alternativas de educación para jóvenes". Publicado en CD ROM IX Jornadas de Sociología. Universidad de Buenos Aires.

GALLART, MARÍA. ANTONIA. (2006). La escuela técnica industrial en Argentina. ¿Un modelo para armar? Uruguay: CINTERFOR/OIT.

INET (2009). Informe del Sector Construcción. Buenos Aires: Instituto Nacional de Educación Tecnológica.

JACINTO, CLAUDIA (2014). "Nuevas lógicas en la formación profesional en Argentina. Redefiniendo lo educativo, lo laboral y lo social". Perfiles Educativos Vol. XXXVII, $\mathrm{N}^{\circ} 148$. México: IISUE-UNAM.

JACINTO, CLAUDIA. (2010). "Introducción. Elementos para un marco analítico de los dispositivos de inserción”. En Jacinto, C. (Comp.) La construcción social de las trayectorias laborales de jóvenes. Políticas, instituciones, dispositivos y subjetividades. Buenos Aires: Teseo-IDES.

JACINTO, CLAUDIA Y HORARIO CHITARRONI. (2010) "Precariedades, rotación y movilidades en las trayectorias laborales juveniles". Estudios del Trabajo, No 39/40. Buenos Aires: ASET.

JACINTO, CLAUDIA Y VERÓNICA MILLENAAR (2009). "Enfoques de programas para la inclusión laboral de los jóvenes pobres: lo institucional como soporte subjetivo". Revista Última Década, $\mathrm{N}^{\mathrm{0}} 30$. Valparaíso: CIDPA.

MARTÍN, MARÍA. EUGENIA Y JULIETA DELLA TORRE. (2012). "Los mercados de trabajo locales desde una perspectiva relacional y su vínculo con las políticas de formación y empleo. El caso de la vitivinicultura mendocina". Estudios Avanzados, $\mathrm{N}^{\mathrm{o}} 18$. 
MILLENAAR, VERÓNICA. (2010). "La incidencia de la formación para el trabajo en la construcción de trayectorias laborales de mujeres jóvenes". En Jacinto; C. (Comp.) La construcción social de las trayectorias laborales de jóvenes. Políticas, instituciones, dispositivos y subjetividades. Buenos Aires: Teseo.

MINGO, GRACIELA ET AL. (2013). "Los indicadores de coyuntura laboral en el sector de la construcción en el marco de la crisis económica internacional y las políticas contra cíclicas en Argentina". Presentado en «11 ${ }^{\circ}$ Congreso Nacional de Estudios del Trabajo». Universidad de Buenos Aires.

MIRANDA, ANA. (2012). "La formación profesional en el sector de la construcción en Argentina". RASE Vol. 5, $\mathrm{N}^{\circ} 1$.

MORROW, ROSEMARY (2010). Guía de Permacultura: para el usuario de la tierra. Bariloche: BRC Ediciones.

PASTRANA, E.; LÓPEZ, C. Y DI FRANCESCO, V. (2008). "Las características del trabajo informal en el sector de la industria de la construcción en el AMBA". Serie Ocupación, Trabajo y Empleo, MTEySS N ${ }^{\circ}$ 8. Buenos Aires.

PERELMAN, LAURA Y PATRICIA VARGAS. (2011). "La experiencia de la privatización de los trabajadores siderúrgicos de SOMISA". Presentado en «X Congreso Argentino de Antropología Social» Universidad de Buenos Aires.

PÉREZ, PABLO. (2008). La inserción ocupacional de los jóvenes en un contexto de desempleo masivo. El caso argentino entre 1995 y 2003. Buenos Aires: Miño y Dávila/CEIL-PIETTE.

RUGGIRELLO, HERNÁN. (2011). "El sector de la construcción en perspectiva: internacionalización e impacto en el mercado de trabajo". Aulas y Andamios, UOCRA: Buenos Aires.

SALVIA, AGUSTÍN. (2008). Jóvenes promesas. Trabajo, educación y exclusión social de jóvenes pobres en la Argentina. Buenos Aires: Miño y Dávila.

SOSA, MARIANA (2015). "La industria de la construcción en la posconvertibilidad (20032014)". Revista Realidad económica, Na 293. Buenos Aires.

\section{Otras fuentes de información:}

- $\quad$ Decreto Nacional N ${ }^{\circ} 1374 / 2011$

- $\quad$ Decreto GCBA No 266/2003

- $\quad$ Ley Nacional $N^{\circ} 24427 / 2008$

- $\quad$ Ley Nacional No 26058/2005.

- $\quad$ Resolución N¹12/2013, Prov. de Buenos Aires

- $\quad$ Programa Aprender Trabajando, GCABA.

- Relevamiento Anual, Dirección Nacional de Información y Evaluación de la Calidad Educativa (DINIECE) 